\title{
Occupancy measurement in building: A litterature review, application on an energy efficiency research demonstrated building
}

\author{
A. Caucheteux ${ }^{1, \star}$, A. Es Sabar ${ }^{1}$, and V. Boucher ${ }^{1}$ \\ CETE Ouest/DLRCA, France
}

Received: 30 May 2013 / Accepted: 16 July 2013

\begin{abstract}
Measuring the energy efficiency of buildings and its confrontation with the current Building Energy Simulations now faces knowledge of what is commonly called "occupancy". This work has been made in order to implement a monitoring system on a research demonstrator building at DLRCA in Angers (France). The goals were first to know the occupancy as input data of models but also to build occupancy models. Occupancy can be defined as all the action of occupants that affect building energy efficiency. The chosen monitoring deals with its presence, lightning, windows opening and internal gains. It seems that the use of an Infra- red detector allows a accuracy of $5 \mathrm{~min}$ in the detection of presence. The use of dry contact sensors allows the detection of five different rates of slide windows opening that can affect temperature decrease. Light sensors seem to be efficient to detect artificial lighting states when correctly configured.
\end{abstract}

Keywords: Occupancy; monitoring; building energy efficiency; occupant behaviour

\section{Introduction}

Measuring the energy efficiency of buildings and its confrontation with the current building energy simulations now faces knowledge of what is commonly called "occupancy" [1-12]. Indeed, the influence of user behaviour on building energy consumption is significant and is increasing as building performance is high. Influence of the occupant can occur through internal gains (heat production by human metabolism or electrical devices use), solar gains (by the use of blinds), ventilation loss (windows opening), etc.

Then a lot of work deals with the modelling of occupancy [13-18] in order to increase accuracy of expected consumption evaluated with building energy simulations.

This work has been made in order to implement a monitoring system on a research demonstrator building at DLRCA in Angers (France). It has been financed by the ANR (French National Research Agency) through the MEMOIRE project. This project deals with an audit method in order to characterize energy efficiency of existing building. It has two main objectives: to precisely identify parameters that have a great influence on building energy behaviour and to develop a model of occupancy.

This paper therefore proposes to define what is meant by occupancy and try to answer the following questions: what to measure, how and why?

\footnotetext{
* Correspondence:

antoine.caucheteux@developpement-durable.gouv.fr
}

\section{Principle of occupancy in building}

\subsection{Occupancy, definition}

Hoes et al. [3] in 2009 give this definition of occupancy: "the presence of people in the building, but also as the actions users take (or not) to influence the indoor environment". We can interpret this definition in relation to our problem of measuring energy performance in buildings: "all actions of the occupant (including presence) that affect building energy consumption".

The different parameters related to the occupancy can be:

- presence of people;

- lighting;

- open doors and windows;

- closing of blinds and shutters;

- use of various devices that radiate heat;

- use of domestic hot water (DHW);

- actions on scenarios (programming heating and ventilation);

- action on set point temperatures;

- etc.

The user behaviour in a given building, according to the occupancy parameters is motivated by several reasons and is most often related to his: visual comfort (open-close blinds and shutters, turn on the light, etc.), thermal comfort or physiological welfare (temperature, humidity, $\mathrm{CO}_{2}$, etc.) [18-21] or other well-being such as unpleasant smells. 
The occupancy therefore depends on many factors: the building itself (design), its location and orientation, the possibility of the action it offers (window opening control systems), its use (office, housing, commerce, industry, etc.), customs and habits of its users, etc.

The occupancy is then specific to a building, to a site, to a given population and a given use. It seems that any change to a building can cause changes in the occupancy and therefore its consequences from an energy standpoint. For example, simply adding blinds or curtains can change the solar gains and then the heat demand. More significant changes such as the complete retrofitting of the envelope, heating systems and ventilation, should induce changes in occupancy.

\subsection{Why measure occupancy?}

Within a context of greenhouse gas emissions reduction and increasing energy costs, assessing buildings energy efficiency becomes more and more essential. It is not only a matter of customer information, but also of building energy efficiency improvement, energy performance contracting or energy expenditure control.

Models to estimate consumption in buildings usually uses occupancy scenarios, often based on an estimated typical behaviour depending upon the use of the building [22]. In the case of new building design, it is difficult to know in advance exactly what will be the behaviour of users. It is therefore logical to rely on standard behaviour. These models can be improved by the knowledge of the stimuli and the creation of behavioural models.

In the case of new buildings, recently delivered, we have to ensure the proper execution and compare the actual building calculations made during its design.

In the case of existing buildings, knowledge of the behaviour of occupants is necessary to know the actual characteristics of the building with respect to energy efficiency. When we do the heat balance of the building, we have to know the part due to the occupancy to identify with certainty those due to the quality of the envelope or operating systems. It also enables us to assess the future use of the renovated building, assuming no change in behaviour after the renovation.

\subsection{What to measure?}

Several approaches to occupancy monitoring can be followed depending upon the study purposes. Indeed, the actions of the occupants respond to stimuli (temperature, light, etc.) and the results of the internal gains or loss of energy. The decision tree leading to gains/losses of energy due to the occupant can be summarized as follows:

$$
\begin{gathered}
\text { stimuli }--->>\text { shares / action }--->>\text { energy effect } \\
\text { (loss or gain, directly or indirectly). }
\end{gathered}
$$

By direct gains or losses we mean directly transformable into energy consumption. For example, the fact of turning on a light directly generates electricity consumption for power, but causes indirect gains for heating by internal inputs. Then, each stimuli/action or action/effect relationship can be modelled by different tools: stochastic models, thermodynamic calculations, etc. [13-18]. These models work but must often be configured: some are immediately transferable, but for others it is more difficult. Moreover, they require knowledge of a number of initial features.

We can therefore choose to measure stimuli, actions or their effects, whether direct or indirect, depending upon the goals of the study and the models used.

\section{Methods for measuring occupancy}

\subsection{Deployment}

The deployment of the monitoring system depends upon the purpose of the measurement and the accuracy we are looking for. Indeed, it is difficult to be exhaustive in this type of measurement; the scale of the building and the issue of sampling should arise. We should prefer a crosssectional survey (many measuring points on rare occasions or a longitudinal one (few measuring points, continuously). Depending upon the purpose of the project, "The need for certainty must be carefully balanced with measurement and analysis costs" [23].

\subsection{Measuring the occupancy with survey}

The most common method used to measure parameters occupancy is survey. The purpose is to ask users to complete surveys about their habits with respect to their presence, lighting, open window, blinds, etc. One can vary the frequency of the surveys to improve the accuracy of the measurement. This method presents low accuracy, even with extensive questionnaires. For example, only $30 \%$ of individuals correctly estimate the average time of window opening [24].

In addition, it is possible to ask users to complete a table showing their daily behaviour hour by hour. This method has the advantage of being lightweight and inexpensive instrumentation. But it is cumbersome for the user. It could present a heavy load in the re-keying of information and is not likely to be very accurate.

For our research objectives of detailed knowledge of the occupancy, we can not be satisfied with this kind of measurement. It could just be used for punctual validation of protocols or for short experiments.

\subsection{Measuring the presence of the occupant}

It is necessary to obtain accurate knowledge of the number of occupants and their location, firstly because an occupant generates power (estimated at $5 \mathrm{~W} / \mathrm{m}^{2}$ of an occupied building [22]), but also because his presence is the first step to all other actions like windows opening. The 
possibilities of this measurement are numerous. The methods presented here are not necessarily concurrent and can be complementary.

We have to keep in mind that measuring the presence of an occupant at his workplace generates an ethical problem: the knowledge of the presence of an employee at his workstation can be misunderstood.

\subsubsection{Accurate measurement of the presence in each room}

A first solution to perform this measurement is a motion detector like a passive infrared motion detector [25], with an application to automatic triggering alarms or light. This kind of measurement should be more accurate than survey, but it still has drawbacks:

- it cannot quantify the number of occupants in a room;

- it needs a lot of sensors and furthermore it is expensive;

- it could lack accuracy since a person still at his workstation but not moving, may go undetected.

Then a second kind of detector uses video camera. There are cheap solutions using a webcam and available free software [26]. Accuracy should be increased by using more high-performance video cameras and more advanced algorithms [27]. However, if the employee is filmed, it could generate supervision problems.

Other solutions are available, using the relationship between a pollutant like $\mathrm{CO}_{2}$ and people presence [28]. This measure should also be used for other purposes like window opening. It is not very accurate either in the number of people or in time. So this kind of measurement should be crossed with another [29].

One way to achieve accuracy should be the use of extensive environmental sensors like pollutant (CO and $\mathrm{CO}_{2}$ ), light, motion and acoustic sensors [29-31].

\subsubsection{Setting the number of people present in the building by counting the inputs-outputs}

Another method to know the number of occupant in a building is to count inputs and outputs of an area, placing sensors at strategic locations. This method is often used for security purposes [32]. This method has the advantage of being lighter in the number of sensors, but not as accurate: it loses spatial accuracy. We should know how many people are occupying the building, but not in every room (office, conference room, break room). It can be implemented in several ways.

The first and cheaper solution uses an infrared barrier. Such a solution makes lots of noise because it is unable, for example, to detect multiple occupants crossing the barrier $[29,33]$.

So other solutions use video cameras $[32,34]$. It seems that this solution, even it is a little more expensive, can still be quite cheap as a web camera should be accurate enough.

Finally, once again, the use of multiple sensors should increase the accuracy [33].

\subsubsection{Other possible solutions}

Depending upon the cost of different methods, the available budget, the expected accuracy, and the building, one can imagine a method based on systems already in place like the data employee presence pointing. As a result, we will then miss, as measurement data, the presence of outside visitors or for places with several buildings, visitors from one building to others (for meetings, etc.). We can sharpen this information by setting up a list of outside visitors, as found in most companies.

At last, some new technologies such as RFID can be used to localise people in a building. All employees and visitors should wear a badge with an RFID chip. Some detectors should be installed in the whole building. It can be very precise and is not as expensive but it presents the problem of employee survey.

\subsection{Measuring the artificial lighting}

The artificial lighting state could be known through the position of the switches $[13,25]$. In existing old buildings, all of them need to be changed. However, to do so is likely to be cumbersome and expensive particularly when geographic accuracy is not necessary.

Another way for overall knowledge of lighting should be global electric consumption measurement, but it depends upon the building's electrical arrangement.

As our work deals with two goals (occupation modelling and building energy efficiency), the stimuli will be measured. As the stimuli deals with illuminance, the idea is to use this kind of measure to identify if the light is on or not.

\subsection{Measure of windows and blinds opening}

These two problems are similar in the way they are measured. Many solutions have been identified, whether by measuring the stimuli, the action or effect. The stimuli deals with comfort conditions like illuminance, indoor temperature and humidity. It should be doubled with outdoor conditions.

Actions like windows, doors or blinds opening, can be directly measure by several means. The first and simple one is the use of dry contact sensors $[24,35]$. For example, reed contact sensors react to a magnetic field generated by a magnet. This approach has the disadvantage of not giving any information about opening rates. Other systems are able to give this rate but are expensive.

We should also measure the effect: this measure is beginning to be deployed. It is due to the evolution of the temperature near the window that we are going to determine if it is open [36].

Presumably the same type of measure for the state of the blinds can be imagined: by measuring the change in illuminance in the room, possibly matched with the outside illuminance. 
Another method uses photographic analysis. For example, Inkarojrit and Paliaga [37] took four pictures a day for 10 days. The analysis of the pictures gives a survey of the windows' state.

\subsection{Contributions to the equipment use internal gains}

The use of electrical devices directly impact the heating load of a building as almost all the electrical power consumed in the building directly heats it. However, the diversity of devices used, attitudes towards these devices and their deployment create many unknowns. It is important to know where the devices are, when they are used and how they emit heat. The simplest solution should be the use of power meters to detect the operations and evaluation of the dissipated energy by a literature review or a specific study.

However, a general measure of power consumption for uses other than lighting, ventilation, hot water, etc. should allow for a comprehensive understanding of the operation of devices, but no details. Furthermore, this measure is simple in the case of new buildings. It may not be possible in existing buildings based on the building electrical arrangement.

\subsection{Adjustment of equipment}

The two following topics are developed in the study of measuring the energy efficiency of buildings in general and do not completely refer to the occupancy.

\subsubsection{Temperature set point (heating and cooling)}

In general, the temperature set points are set at the control system (the boiler, building automation system (BAS)) for the whole building. The presence of thermostatic valves can be used to refine these adjustments room by room. However, the actual temperature measurement provides detailed knowledge of the actual temperature, and allows us to establish precise and real heating scenarios. For the design of the instrumentation of an entire building, we must focus on measurement accuracy in each room or place the sensors in order to estimate the average temperature of the building, taking the assumption of repeatability temperatures through use. For example, we should measure several office temperatures (north and south), some temperatures in the "common" areas (corridor) and meeting rooms. A statistical study should be initially conducted to estimate the variability of temperatures depending upon the rooms.

\subsubsection{Ventilation scenarios}

The action of occupants in terms of ventilation only deals with the scenario of low and high flow ventilation. In general, the ventilation unit is common to the whole building

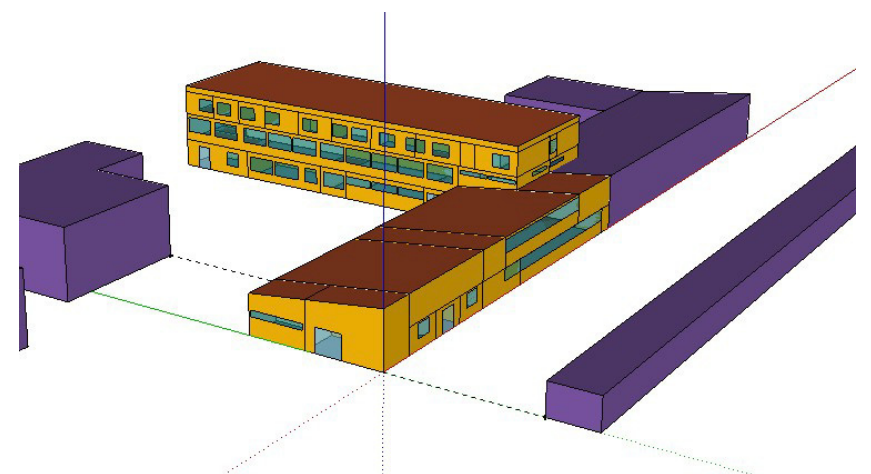

Fig. 1. 3D representation of the monitored building.

or area, and subsequently, its scenario. As for the temperature set point scenario, ventilation scenario is set at the BAS and then should be known. A cross-sectional survey should be made for a week to confirm the scenario.

\subsection{Domestic hot water (DHW)}

Typically, domestic hot water consumption has direct and indirect consequences: energy consumption to produce hot water and grey water energy recovery in the heated volume [38]. The problem of measurement is, therefore, on two levels:

- DHW consumed amount;

- evaluation of the ensued internal gains.

Typically, metering DHW is generally at the system level (flow + temperature). This gives the consumption for the entire building. We can provide localized meters to separate, for example, needs by accommodation or function areas (offices/process). The difficulty lies in the interpretation of this provision in internal gains (latent or sensitive).

\section{Application for a research demonstrator building}

In order to validate the MEMOIRE audit method, a commercial building has been monitored. More than 150 sensors have been deployed through the entire building. A comprehensive audit has been made thanks to archive documents and thorough visits. Figure 1 presents the building with a 3 dimension drawing. It is $1000 \mathrm{~m}^{2}$ and has several areas very different from one to another. Some are built with blocks, other in wood. Some have single flue ventilation and others double. So the building can be divided into several sections. Each section has been defined to present one construction material, one ventilating system and one heating system. The first area, we particularly monitored, is made with blocks without insulation and single constant flue ventilated high temperature distributed heating. A second area is made with blocks with indoor insulation and double flue ventilated, high temperature distributed 
heating. A third area is made with wood and spread insulation, electrical heater heat and single hygro ventilation.

In order to develop and validate occupancy models, we focused the monitoring on the first zone which is composed of six offices. We therefore chose to measure the following parameters:

- presence of occupant;

- lighting state;

- windows state;

- internal gains.

Several solutions can be used for each parameter, we finally chose:

- illuminance for lightning;

- passive infrared (PIR) motion detector for presence;

- infrared barrier for entering and exiting;

- door and windows state detectors;

- electricity uses consumption for internal gains.

Note that temperature and humidity sensors have been placed in each room at about $1.5 \mathrm{~m}$ high, on an inside wall, far from windows and doors.

The following section deals with the validation of the monitoring results in regards to our needs and evaluation of the accuracy of the measurement protocols.

\subsection{Generalities}

We used a wireless system. Pulse counter/binary acquisition device with three inputs are used for connecting PIR, dry contact sensors or infrared barriers. Ambient light sensors are used for light measurements. A gate with an Ethernet TCP/IP interface concentrates the data which are collected by a computer through the TCP/IP network.

\subsection{Building occupancy manual acquisition system (BOMAS)}

In order to test experimental measurements, a crosssectional survey has been made in which we have to know as precisely as possible the occupant behaviour. So we sometimes ask people to note all of their actions. But it appears that it is very cumbersome and not as precise as it needs to be to validate the monitoring conducted. Next, we developed a tool that is called BOMAS (Building Occupancy Manual Acquisition System). It consists of a small program installed on an old computer. The occupant just has to push different switches on the keyboard to note his actions. For example: "escape" when he leaves, "enter" when he enters into the room: no more need to watch time, to find a pen, etc. The computer can be placed just near the door so it becomes very easy for the user not to forget an action. Figure 2 shows the tools: the green button indicates that blinds are open. A label indicates the number of people that are present in the room, etc. The program just saves all events. This tool is very helpful for a short experiment (a week). It loses accuracy over time with use: people forgot to push the switch particularly for blinds.

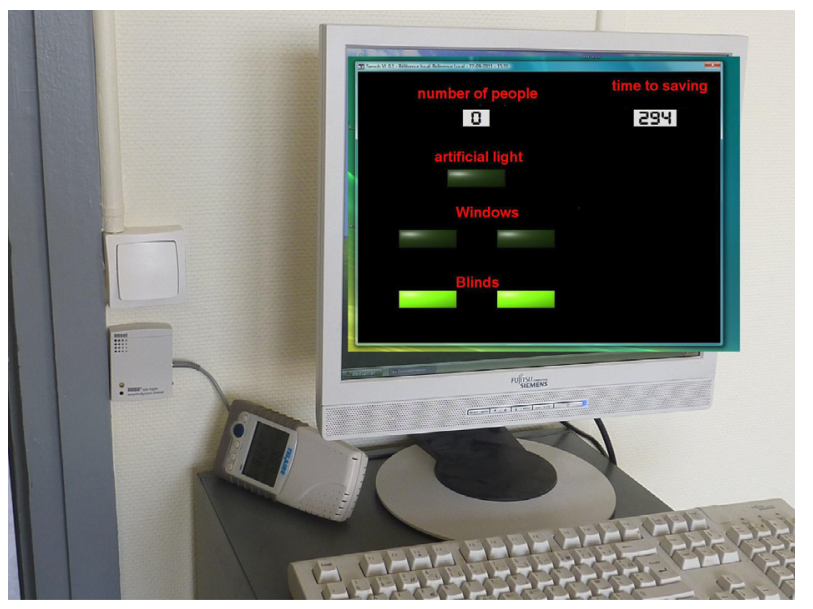

Fig. 2. The building occupancy manual acquisition system.
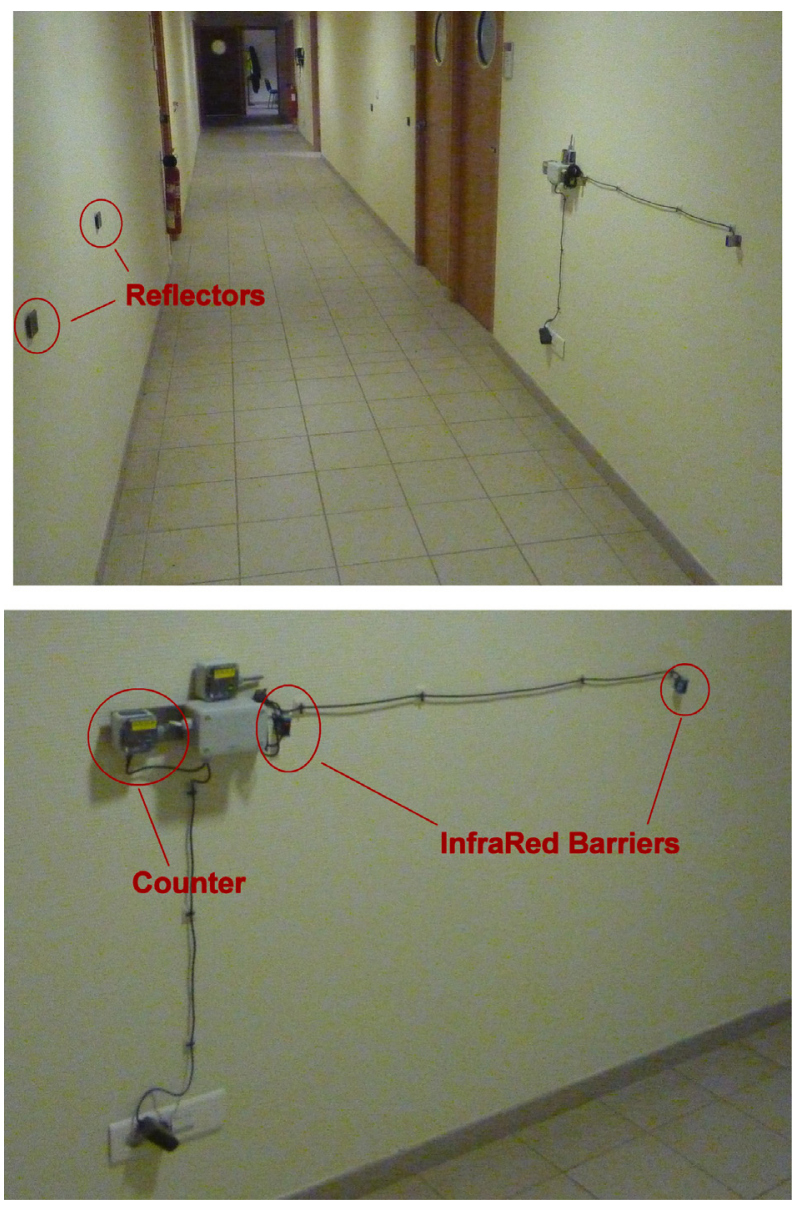

Fig. 3. Area inputs/outputs monitoring with Infrared Barriers.

\subsection{Inputs/outputs of an area}

Measurement of people inputs and outputs for an area has been made by the use of infrared barriers. For each access of a zone, two barriers have been placed one meter apart from each other (Fig. 3).

Each time a barrier is crossed, the counter increases with the rising edge of the digital signal. It is saved with a 


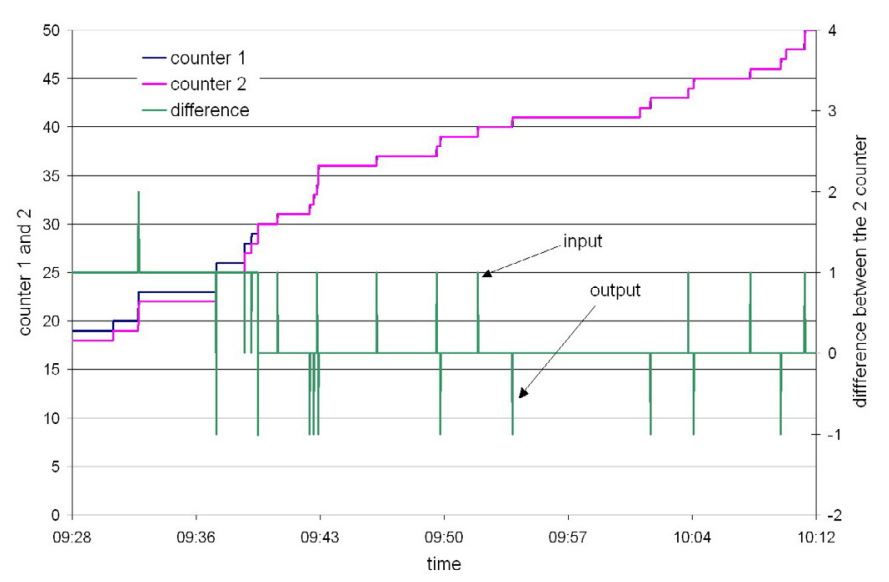

Fig. 4. Inputs and outputs detection with infrared barriers.

step of one second. Then the gap between the two counters gives the way (input or output of the zone).

Figure 4 presents the plots of the saved measurements. Two curves correspond to the two barriers signals, the last one being the difference between the two counters. Then when nobody came through the barriers, the difference between the two counters should be zero. When it is not, the sign (positive or negative) gives the way people go (input or output). The hypothesis is made that people came through the two barriers within a one-second interval.

As already shown by Ekwevugbe et al. [29] and Hutchins et al. [34], the limits of the method are:

- the way the circulation could only be detected if people do not come through the two barriers within the same second;

- when two people do not come through the barrier at the same time, the infrared barrier is then cut only one time;

- people do not have to stop between the two barriers;

- people must not go back between the two barriers;

- arm movement should give interference in the measurements (it is possible to filter).

\subsection{Detection of presence}

Passive infra red (PIR) motion sensors have been installed in the six offices in the first area. Tests have then been performed to determine whether such a device is robust in detecting presence in the office and to what accuracy. After some detection observation for different locations of the sensor, we set up and implemented one of these sensors closest to the workstation on a wall (Fig. 5). The measure was doubled by the BOMAS, allowing a simplified input of the presence of occupants in the office. The motion sensor is connected to a pulse counter for detecting the state of the detector with both rising and falling edge detection of the digital signal. This device was tested from 11 October to 16 October 2012. BOMAS does inventory every $5 \mathrm{~min}$ whether or not there is a presence. A system with PIR motion detection records events (transition from State 1

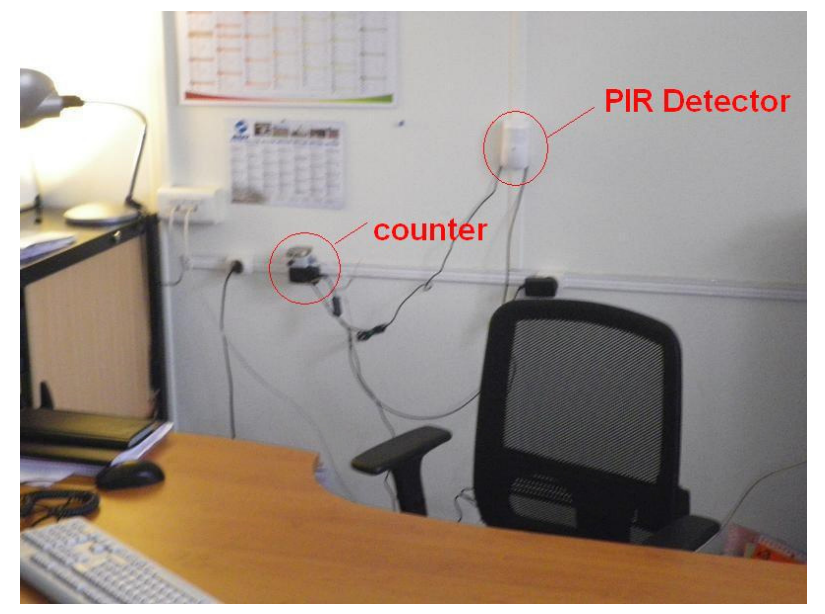

Fig. 5. Example of location of the PIR motion detector.

Table 1. Balance differences between PIR and BOMAS.

\begin{tabular}{cc}
\hline & hh:mm:ss \\
\hline min & $00: 00: 00$ \\
max & $00: 13: 23$ \\
Average & $00: 01: 59$ \\
Mean bias & $00: 02: 44$ \\
\hline
\end{tabular}

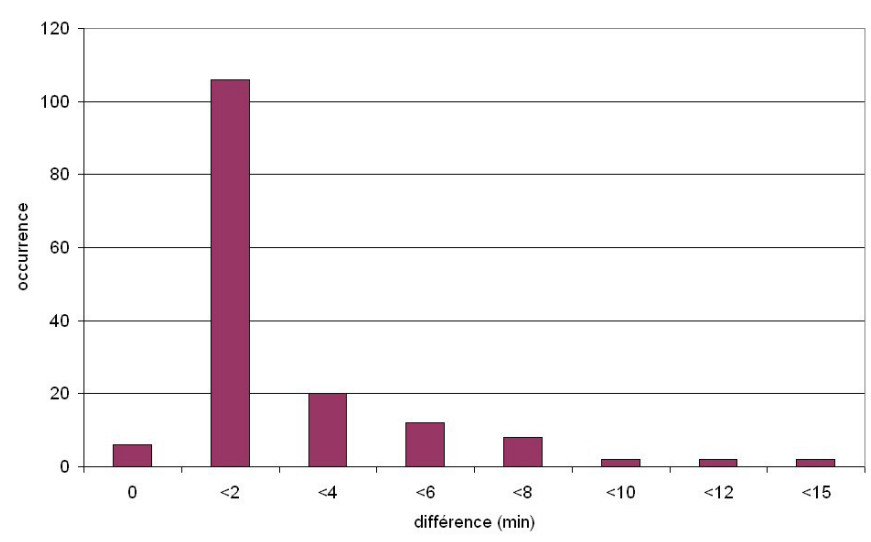

Fig. 6. Distribution of temporal accuracy: occurrence as a function of difference.

to State 0 and vice versa). This is to compare the results of the two measurement systems. The comparison principle is as follows:

- at each BOMAS time step lasting 5 min, we look for the closest event detected by the PIR;

- we calculate the time difference with the nearest event recorded by the BOMAS.

Thus, we are able to provide indicative timing of the presence detection by this system in the office. Table 1 shows the difference in minimum, maximum, average and standard deviation recorded during the test. Figure 6 shows the distribution of these differences. It is, thus, determined that the uncertainty of the presence of one or more occupants in an office determined by the PIR sensor is less 


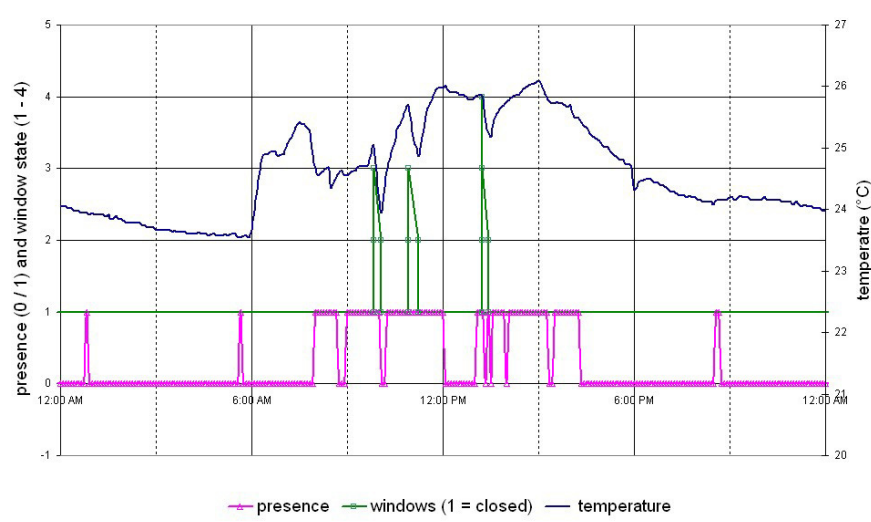

Fig. 7. Result of monitoring for one office (presence, windows and temperature).

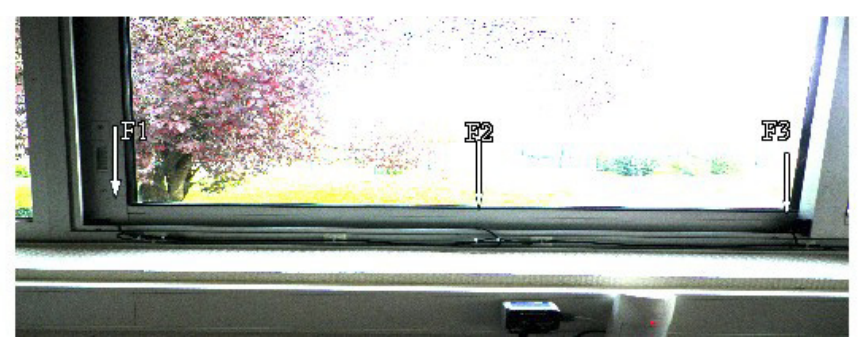

Fig. 8. Windows monitoring dry contact sensors position.

than 5 min to the tested desktop. It corresponds to our recording step.

For example, Figure 7 presents presence, windows opening and temperature monitoring in one office on the day of 21 November 2012. We can observe the presence of the employee in his office from 8:05 a.m. to 12:00 p.m. and from 1:10 p.m. to 16:15 p.m. Some presence was seen at 0:50 a.m., 5:40 a.m. and 8:40 p.m.: it corresponds to the security employee that makes his patrol rounds.

\subsection{Windows}

Opening windows sensors were placed on the windows of Zone 1 which consisted of sliding windows. The detection of the opening of a window is carried out by means of three reed contact sensors whose position is shown in Figure 8. The sensors are connected to the three inputs of a pulse detector, respectively. The crossing of one of them sends alarms on the state of the three sensors. The position of the sensors corresponds to the following state of the window:

- F1: closed;

- F2: $50 \%$ opened;

- F3: 100\% opened.

F1, F2 and F3 are magnets fixed on the frame of the window. One magnet is fixed on the sliding part of the window. The analyses of the three sensors' data file allow us to distinguish five positions of the window, depending upon the position of the movable element: $\mathrm{P} 1=$ closed,

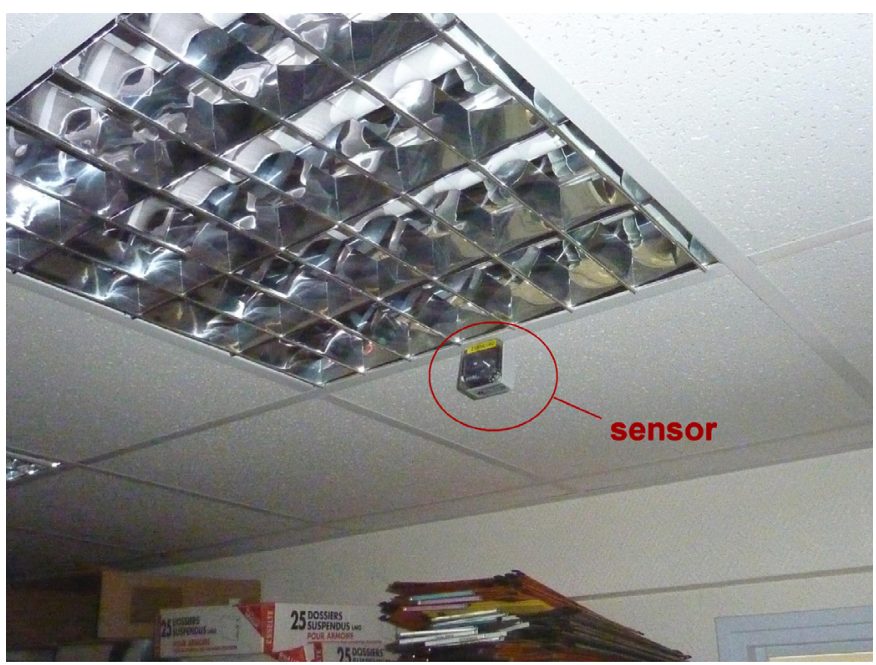

Fig. 9. Example of position of a light sensor for lighting detection.

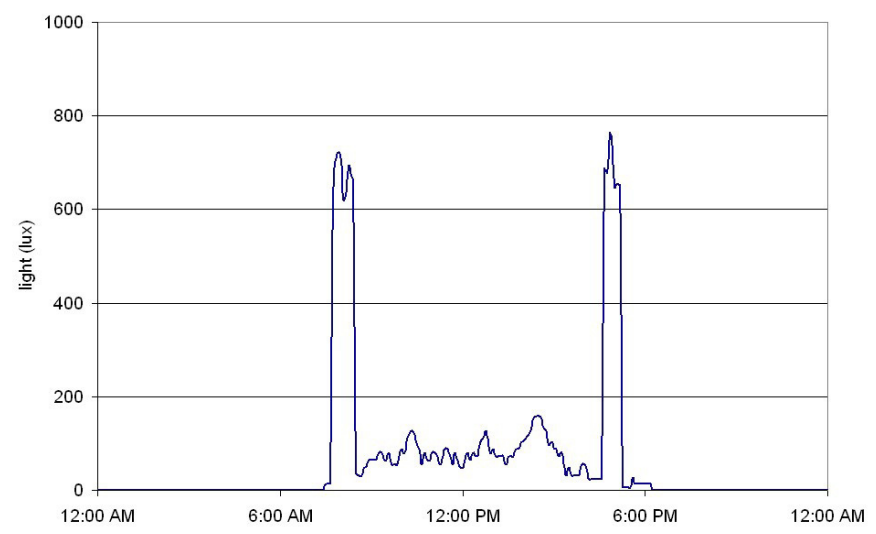

Fig. 10. Light measured in an office during one working day.

P3 = half-opened, P5 $=100 \%$ opened, P2 and P4 intermediate positions.

For example, we observed on Figure 7 a window opening at 9:50 a.m., 10:55 a.m. and 1:12 p.m. and a sudden decrease of temperature at the same time.

\subsection{Lighting}

The purpose is to collect information about the artificial lighting state of an office (on or off). We use ambient light sensors placed next to lamps. Figure 9 present a picture of an example of position of the sensors. It was placed in the darkest area of the room. In our configuration, in most offices, it appears that in the absence of artificial light, measured illuminance should be under 200 lux. When the lighting is on: it should measure more than 600 lux. In other offices, it is sometimes necessary to compare it with a measurement from another light sensor in the office or from an outdoor light sensor. Figure 10 gives an example of measurement made where we easily identify the period where artificial lighting has been used. 


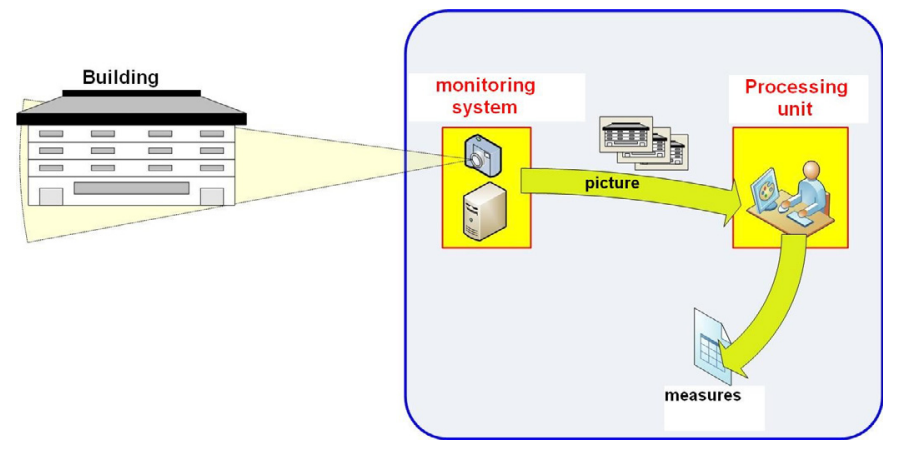

Fig. 11. Video camera system for windows and blinds monitoring.

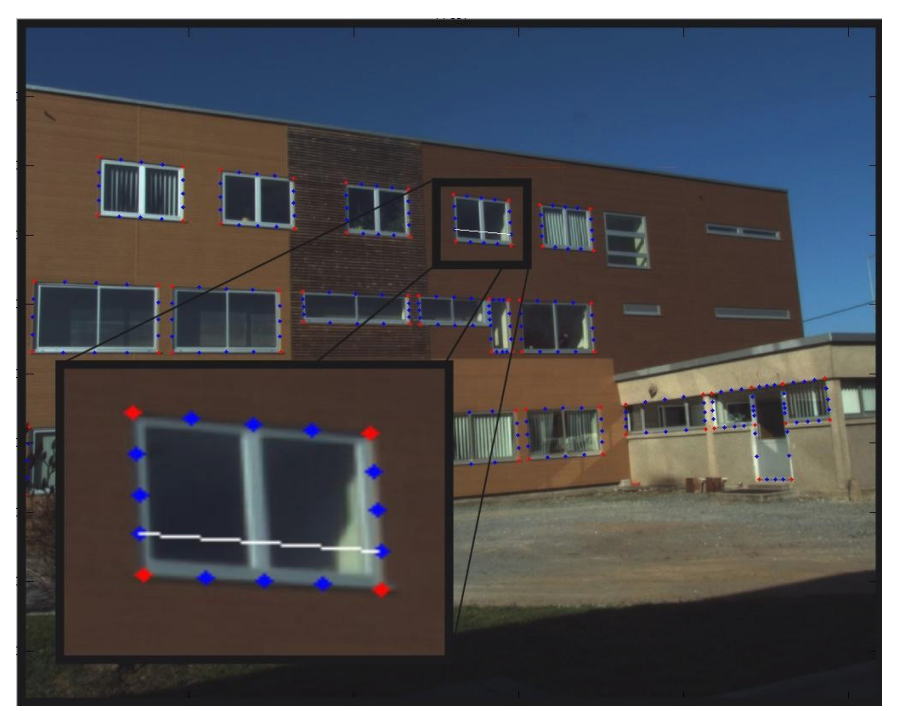

Fig. 12. Picture of the building for windows and blinds opening detection, example: open blind.

\subsection{Window and blind state by camera}

As we have just seen, the chosen monitoring of windows opening, even if it is quite cheap, is very intrusive and time consuming for installation and interpretation for a whole building. So, inspired by the Inkarojrit and Paliaga [37] experiment, we tested a prototypic device. The measurement system is based on video camera survey of the front wall of a building. The system, that is presented in Figure 11, consists of:

- a video camera that takes photographs (1 per s) and transfers them to the processing unit;

- a processing module which analyzes photographs and calculates openings. It could be transferred on a standard desktop computer station.

After a phase of configuration and calibration, the processing module performs as automatically as possible, measurements of openings. Figures 12 and 13 present an example of identification with 2 consecutives pictures of a blind that has been closed. Every window of the picture has been identified in the configuration process (red and blue points). Then all the windows on the picture can be

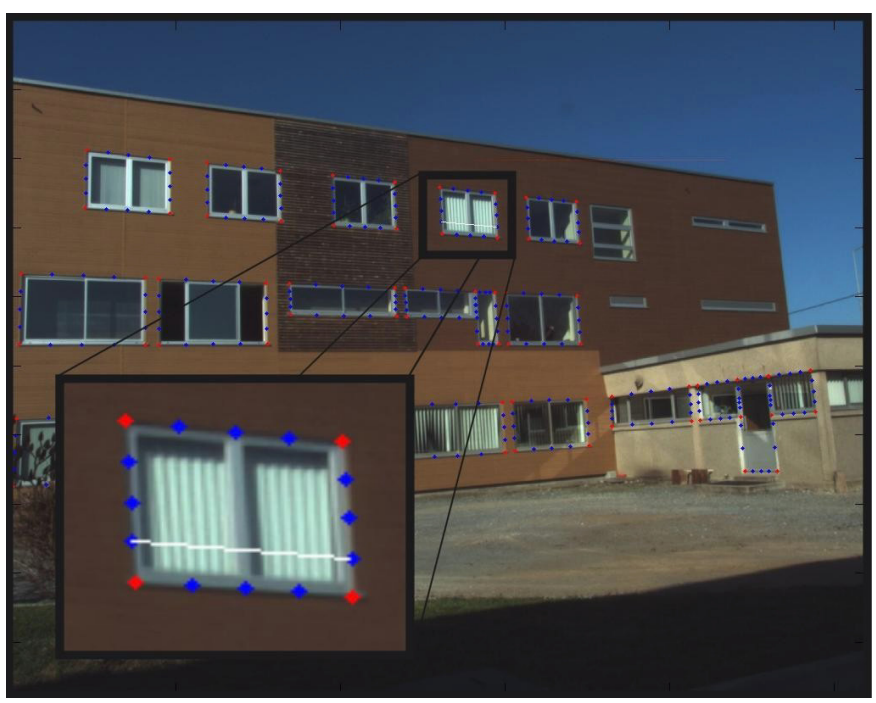

Fig. 13. Picture of the building for windows and blinds opening detection, example: closed blind.

followed by the system. The two pictures show an opened and closed blind. The system is able to identify not only that the blind is open or closed, but how many as well.

This device should not only be able to identify the positions of the blinds, but also windows opening. In some cases, we expect that it could be possible to identify artificial light switching.

\section{Conclusion}

Measuring occupancy should be required to improve energy efficiency characterization. We have shown that for each topic, there are several methods possible. These methods present different material costs, different human costs and different accuracy. The choice of the devices will depend upon the goals of the driven study. Indeed, in our case of both modelling occupancy and a validated audit method, great accuracy is expected. So we sometimes measure parameters in several ways.

Nowadays, analysis of data should give us a way to decrease the required device number. For example, will video cameras allow us to be accurate enough in blinds, windows and perhaps light detection? Would it be possible to make a link between temperature and window opening? Would it be accurate enough for research purposes? Would the electrical consumption allow us to know the presence rate in the building? How many sensors are needed and to what accuracy?

Acknowledgements. Part of this work has been supported by the French National Research Agency (ANR) through the Habitat Intelligent et Solaire Photovoltaïque Program (projet MEMOIRE ANR-10-HABISOL-006) and by the French Ministry of Ecology. 


\section{References}

1. C.M. Clevenger, J. Haymaker, The impact of the building occupant on energy modeling simulations, in Joint International Conference on Computing and Decision Making in Civil and Building Engineering, Montreal, Canada, 2006, pp. 3637-3646

2. A. Mahdavi, C. Proglhof, User behavior and energy performance in buildings, Internationalen Energiewirtschaftagung an der TU Wien, IEWT (2009)

3. P. Hoes, J.L.M. Hensen, M.G.L.C. Loomans, B. de Vries, D. Bougeois, User behavior in whole building simulation, Energy Build. 41, 295-302 (2009)

4. W. Parys, D. Saelens, H. Hens, Implementing realistic occupant behavior in building energy simulations the effect on the results of an optimization of office buildings, in Proceedings of the 10th REHVA World Congress Sustainable Energy use in Buildings, Antalya, 2010, pp. 1-8

5. D. Bourgeois, J. Hand, I. Mcdonald, C. Reinhart, Adding sub-hourly occupancy prediction, occupancy-sensing control and manual environmental control to ESP-r, in Proceeding of Esim 2004, Vancouver, BC, 2004, pp. 119 126

6. K. Roth, P. Engelmann, Impact of user behavior on energy consumption in high performance buildings results from two case studies (Fraunhofer Center for Sustainable Energy Systems, Denver, CO, 2010)

7. J. Pfafferott, S. Herkel, Statistical simulation of user behaviour in low energy office buildings, in International Conference passive and low energy cooling for the built environment, Santorini, Greece, 2005, pp. 721-726

8. J. Seryak, K. Kissock, Occupancy and behavioural affects on residential energy use, in Proceedings of the Solar Energy Conference, Kohala Coast, Hawaii, 2003

9. D. Lindelof, N. Morel, A field investigation of the intermediate light swithing by users, Energy Build. 38, 790-801 (2006)

10. D. Bourgeois, C. Reinhart, I. Macdonald, Adding advanced behavioural models in whole building energy simulation: a study on the total energy impact of manual and automated lighting control, Energy Build. 38, 814-823 (2006)

11. D. Bourgeois, C. Reinhart, I. Macdonald, Assessing the total energy impact of occupant behavioural response to manual and automated lighting systems, in Proceedings of the buildings simulaton 2005, Montreal, Canada, 2005, pp. 1-8

12. F. Nicol, H. Rijal, M. Humphreys, Characterising the use of windows in thermal simulation, in 2nd PALENC Conference and 28th AIVC Conference on building low energy cooling and advanced ventilation technologies in the 21st century, Crete Island, Greece, 2007

13. F. Haldi, Towards a unified model of occupants' behaviour and comfort for building energy simulation, Ph.D. thesis, École polytechnique fédérale de Lausanne, 2010

14. J. Page, Simulating occupant presence and behaviour in buildings, Ph.D. thesis, École polytechnique fédérale de Lausanne, 2007

15. G. Zimmermann, Modeling and simulation of individual user behavior for building performance predictions, in Proceedings of the 2007 Summer Computer Simulation Conference, SCSC 200\%, San Diego, California, 200\%, pp. $913-920$
16. D. Bourgeois, Detailed occupancy prediction, occupancysensing control and advanced behavioural modelling within whole building energy simulation, Ph.D. thesis, Université Laval, 2005

17. J.F. Nicol, Characterising occupant behaviour in buildings: toward a stochastic model of occupant use of windows, lights, blinds, heaters and fans, in Proceedings of 7 th IBPSA conference, IBPSA 2001, Rio de Janeiro, Brazil, 2001, pp. 1073-1078

18. B. Moujalled, Modélisation dynamique du confort thermique dans les bâtiments naturellement ventilés, Ph.D. thesis, INSA, Lyon, 2007

19. P. Tuohy, H.B. Rijal, M.A. Humphreys, J.F. Nicol, A. Samuel, J. Clarke, Comfort driven adaptative window opening behavior and the influence of building design, in Proceeding of Building Simulation 2007, 10th IBPSA Conference, pp. 717-724

20. R. Cantin, B. Moujalled, G. Guarrano, Complexité du confort thermique dans les bâtiments, in $b^{e}$ congrès Européen de science des systèmes, Paris, France, 2005

21. F. Thellier, F. Monchoux, M. Endravadan, Prise en compte du comportement adaptatif de l'être humain dans la simulation thermique de l'habitat, in Congrès Français de Thermique, Île des Embiez, 2007

22. CSTB. Réglementation thermique 2005, French Code on Envelope Thermal Performance for Buildings, 2006

23. ASHRAE 2002, Measurement of energy and demand savings, ASHRAE Guideline 14-2002, Atlanta, GA, 2002

24. B. Fleury, P. Niard, Comportement des occupants vis-à-vis de l'ouverture des fenêtres. Électricité de France, direction des études et recherches, service application de l'électricité et environnement, département application de l'électricité, Groupe habitat, novembre 1990

25. D. Delaney, G. O'Hare, A. Ruzzelli, Evaluation of energyefficiency in lighting systems using sensor networks, in Proceedings of the First ACM Workshop, on Embedded Sensing Systems for Energy Efficiency in Buildings, Berkeley, CA, USA, 2009, pp. 61-66

26. R. Donzel, Low cost energy and occupancy monitoring system with high time resolution for non weather dependant appliances, Fourth year internship report (INSA Lyon, Berkeley lab.), 2008

27. N. Cordier, Développement de stratégies de contrôle de ventilation appliquées aux locaux de grande dimension, Ph.D. thesis, INSA Lyon, Institut National des Sciences Appliquées, 2007

28. A. Ansanay, Estimating occupancy using indoor carbon dioxide concentrations only in an office building: a method and qualitative assessment, CLIMA 2013, in 8th International Conference on IAQVEC, 2013 (to appear)

29. T. Ekwevugbe, N. Brown, D. Fan, Using indoor climatic measurements for occupancy, monitoring, in Proceedings of 4th West Africa, Built Environment Research (WABER) Conference, 2012, Abuja, Nigeria, edited by S. Laryea, S.A. Agyepong, R. Leiringer, W. Hughes, pp. 507-520

30. D. Bing, A. Burton, Sensor based occupancy behavioral pattern recognition for energy and confort management in intelligent buildings, in 11th International IBPSA Conference, Glasgow, Scotland, 2009

31. K. Lam, M. Hoynck, B. Dong, B. Andrews, Y. Chiou, R. Zhang, D. Benitez, J. Choi, Occupancy detection through an extensive environmental sensor network in an open plan office building, in 11th International IBPSA Conference, Glasgow, Scotland, 2009, pp. 1452-1459 
32. R. Tomastik, Y. Lin, A. Banaszuk, Video based estimation of building occupancy during emergency egress, in Proceeding of American control Conference, Washington, USA, 2008

33. V.L. Erickson, Y. Lin, A. Kamthe, R. Brahme, A. Surana, A. Cerpa, M. Sohn, S. Narayanan, Energy efficient building environment control strategies using real time occupancy measurements, in Proceedings of the First ACM Workshop on Embedded Sensing Systems for Energy-Efficiency in Buildings (BuildSys '09), Berkeley, California, 2009, pp. 19-24

34. J. Hutchins, A. Ihler, P. Smyth, Modeling count data from multiple sensors: a building occupancy model, in $2 n d$ IEEE International Workshop on Computational advances in multi sensor adaptative processing (CAMPSAP), 2007, pp. 241-244
35. E. Lemerrer, E. Cayre, C. Vota, Gestion de l'énergie par les contacts de feuillure. Électricité de France, direction des études et recherches, service application de l'électricité et environnement, département application de l'électricité, Groupe habitat EDF, juillet 1994

36. H.B. Rijal, P. Tuohy, F. Nicol, M.A. Humphreys, J. Clarke, A window opening algorithm and UK office temperature: fiel results and thermal simulation, Building simulation, 2007

37. V. Inkarojrit, G. Paliaga, Indoor climatic influences on the operation of windows in a naturally ventilated building, in 12th Conference on passive and low energy architecture, Eindhoven, The Nederlands, 2004

38. P. Eslami-nejad, M. Bernier, Impact of grey water heat recovery on the electrical demand of domestic hot water heaters, in 11th IBPSA Conference, Glasgow, 2009 